\title{
Esophageal Hemangioma
}

National Cancer Institute

\section{Source}

National Cancer Institute. Esophageal Hemangioma. NCI Thesaurus. Code C95622.

A capillary or cavernous hemangioma that arises from the esophagus. The majority of cases are polypoid intraluminal lesions. 